Pacific Journal of Mathematics

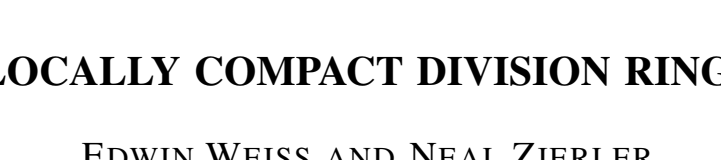




\section{LOCALLY COMPACT DIVISION RINGS}

\section{EDWin Weiss and Neal ZierLer}

Let $K$ be a division ring with a non-discrete topology $T$ with respect to which both the additive group $K^{+}$and the multiplicative group $K^{*}$ of $K$ are locally compact topological groups. ${ }^{1}$ If $m$ is Haar measure for $K^{+}$and $a \in K$, the function $m^{\prime}(E)=m(a E)$ is clearly an invariant Borel measure for $K^{+}$. Hence there exists a real number $\phi(a)$ such that $m^{\prime}(E)=\phi(a) m(E)$ for all Borel subsets $E$ of $K^{+}$. The real-valued function $\phi$ on $K$ (which is essentially the Radon-Nikodym derivative of $m$ with respect to left-invariant Haar measure on $K^{*}$ ) evidently has the first two of the following three properties.

(1) $\phi(a) \geqq 0 ; \phi(a)=0$ if and only if $a=0$.

(2) $\phi(a b)=\phi(a) \phi(b)$.

(3) There exists $M>0$ such that $\phi(a) \leqq 1$ implies $\phi(1+a) \leqq M$.

We shall show that $\phi$ satisfies (3) also, i. e., is a valuation for $K$, and that the topology $T_{\phi}$ for $K$ defined by $\phi$ coincides with $T .^{2}$ The classification of $K$ then follows from known results.

\section{LEMMA $1 . \phi$ is continuous.}

Proof. Let $\varepsilon$ be a positive number and let $E$ be a compact set of positive measure. By the regularity of Haar measure we may choose an open set $U$ containing $E$ such that $m(U)-m(E)<\varepsilon m(E)$. Choose a neighborhood $V$ of 1 with $V=V^{-1}$ and $V \cdot E \subset U$. Then for $x$ in $V$, $\phi(x)=m(x E) / m(E) \leqq m(U) / m(E)<1+\varepsilon ;$ since $x^{-1} \in V, \phi(x)=\left(\phi\left(x^{-1}\right)\right)^{-1}>$ $(1+\varepsilon)^{-1}$. Hence $1-\varepsilon<\phi(x)<1+\varepsilon$ and the continuity of $\phi$ on $K^{*}$ follows, ${ }^{2 *}$ Now choose an open set $U$ with $m(U)<\varepsilon m(E)$ and a neighborhood $V$ of 0 with $V \cdot E \subset U$. Then for a in $V, \phi(a)=m(a E) / m(E) \leqq m(U) / m(E)<\varepsilon$ and $\phi$ is continuous at 0 .

LEMMA 2. $S=\{a \in K: \phi(a) \leqq 1\}$ is compact.

Received February 13, 1958 and in revised form April 1, 1958,

The research in this paper was supported jointly by the Army, Navy and Air Force under contract with the Massachusetts Institute of Technology. The first author is a consultant, Lincoln Laboratory, M. I. T. The second author is a staff member, Lincoln Laboratory, M. I. T.

1 Continuity of the inverse multiplicative operation need not be assumed; $c f$. the concluding remark. The continuity of multiplication implies that $a \rightarrow-a=(-1)$. a is continuous.

2 This idea was suggested by some work of Tate, [12].

${ }^{2 *}$ Cf. Halmos [3, §60.6, p. 265]. 
Proof. Let $C$ be a compact neighborhood of 0 and choose a neighborhood $V$ of 0 such that $V \cdot C \subset C$. Let $a \in V \cap C$ such that $0<\phi(a)<$ 1. If $a^{n} S \subset C$ holds for no $n=1,2, \cdots$, we select for each $n$ an $s_{n} \in S$ such that $a^{n} s_{n} \notin C$. Since $\phi\left(a^{k}\right) \rightarrow 0$ and all the $a^{k}$ lie in the compact set $C, a^{k} \rightarrow 0$ and hence $a^{k} s_{n} \in C$ for sufficiently large $k$. We may therefore choose $k_{n} \geqq n$ such that $a^{k} n s_{n} \notin C$ but $a^{k} n^{+1} s_{n} \in C$. Then the sequence $\left\{a^{k} n s_{n}\right\}$ of elements of the compact set $a^{-1} C$ has a cluster point $c$ in $a^{-1} C$. Hence $\phi\left(a^{k} n \xi_{n}\right)=\phi(a)^{k} n \phi\left(s_{n}\right) \leqq \phi(a)^{k} n$ has $\phi(c)$ as a cluster point by the continuity of $\phi$; thus $\phi(c)=0$ and $c=0$, which contradicts $a^{k} n s_{n} \notin$ $C$. It follows that $S$ is a subset of the compact set $a^{-n} C$ for some $n$ and so, being closed by virtue of the continuity of $\phi$, is compact.

Corollary. $\phi$ is a valuation.

Proof. $\phi(1+S)$, the continuous image of the compact set $1+S$, is bounded.

LEMMA 3. $T_{\phi}=T$.

Proof. Let $V \in T-\{\phi\}, a \in V$ and $B_{n}=\left\{b \in K: \phi(b-a)<2^{-n}\right\}$. Suppose we can choose $b_{n} \in B_{n}$ with $b_{n} \notin V$ for each $n=1,2, \cdots$. But then the points $b_{n}-a$, all of which lie in the compact set $S$, have a cluster point $c$ in $S$ which must be 0 since $\phi(c)=0$. Hence $b_{n} \rightarrow a$ contrary to our assumption and it follows that $T \subset T_{\phi}$. Since the opposite inclusion is an immediate consequence of the continuity of $\phi$, the proof is complete.

If $K$ is connected ${ }^{3}$, it is the real, complex or quaternion field (Pontrjagin [10]); in particular, $\phi$ is archimedean. Conversely, if $\phi$ is archimedean, the theorem of Ostrowski [8, p. 278] asserts that the center of $K$ is either the real or complex field and so $K$, not being totally disconnected, is connected. ${ }^{5}$

If $K$ is totally disconnected, $\phi$ is non-archimedean (and conversely, according to the above) and results due to van Dantzig [2], Hasse [4], Hasse and Schmidt [5], Jacobson and Taussky [6] and Jacobson [7] assert that $K$ is of one of the following three types; ${ }^{4}$

(i) the completion of an algebraic number field at a finite prime,

(ii) the completion of an algebraic function field in one variable

${ }^{3} K$ is either connected or totally disconnected: if the component $C$ of 0 contains $a \notin$ 0 then $b a^{-1} C$ is a connected set containing 0 and $b \in K$.

${ }^{4}$ Otobe [9] shows that $a \rightarrow a^{-1}$ need not be assumed to be continuous; cf. our final remark in this connection.

5 Alternatively, if $K$ is connected, it is not difficult to show that $\phi$ is archemedian; then $K$ is a vector space over the reals (Ostrowski) with $\phi$ as a norm, hence is the real, complex or quaternion field (Arens [1] Tornheim [13]), proving Pontrjagin's theorem. 
over a finite field $H$,

(iii) a division ring $D$ obtained from a field $F$ of type (ii) by redefining $x . a=a^{\sigma} . x, a \in H, \sigma$ a fixed non-trivial automorphism of $H$, the elements of $D$ and $F$ being regarded as power series $\sum_{i=n}^{\infty} a_{i} x^{i}$ in an indeterminate $x$ over $H$ with coefficients in $H$.

REMARK. Continuity of $a \rightarrow a^{-1}$ need not be assumed, for it appears in the connected case only in the proof that $K$ is not compact in the proof of the Pontrjagin theorem [11, p. 173, Theorem 45.]. If $K$ were compact, $\phi(a)=m(a K) / m(K) \leqq 1$ for all $a \in K$. But, as in the proof of the continuity of $\phi$ at 0 in Lemma 1 , we can find $a \in K$ such that $0<$ $\phi(a)<1$; then $\phi\left(a^{-1}\right)>1$ and it follows that $K$ is not compact. If $K$ is totally disconnected we have only to apply to $T, K^{*}$ the following unpublished theorem of A. M. Gleason: Let $G$ be a group with a totally disconneted topology $T$ under which the group operation is continuous from $G \times G$ to $G$. Then $T, G$ is a topological group.

\section{REFERENCES}

1. R. Arens, Linear topological division algebras, Bull. Amer. Math. Soc., 53 (1949), 623-630.

2. D. van Dantzig, Studien over topologische Algebra, Dissertation, Amsterdam, 1931.

3. P. Halmos, Measure theory, van Nostrand, New York, 1950.

4. H. Hasse, Uber p-adische Schiefkörper und hyperkomplexe Zahlysysteme, Math. Ann. 104 (1931), 495-534.

5. H. Hasse and F. R. Schmidt, Die Struktur diskret bewerteter Körper, J. reine ang. Math. 170 (1934), 4-63.

6. N. Jacobson and O. Taussky, Locally compact rings, Proc. Not. Acad. Sci, 20(1935), 106-108.

7. N. Jacobson, Totally disconnected locally compact rings, Amer. J. Math., 58 (1936), 433-449.

8. A. Ostrowski, Über einige Lösugen der Funktionalgleichung $\phi(x) \phi(y)=\phi(x y)$, Acta Math., 41 (1917), 271-284.

9. Y. Otobe, On locally compact fields, Jap. J. Math. 19 (1945), 189-202.

10. L. Pontrjagin, Über stetige algebraische Körper, Ann. Math. 33 (1932), 163-174.

11. L. Pontrjagin, Topological groups, Princeton, 1939.

12. J. T. Tate, Thesis, Princeton, 1950.

13. L. Tornheim, Normed fields over the real and complex fields, Michigan Math. I. 1 (1952), 61-68.

MASSACHUSETTS INSTITUTE OF TECHNOLOGY 



\section{PACIFIC JOURNAL OF MATHEMATICS}

\section{EDITORS}

\section{H. L. Royden}

Stanford University

Stanford, California

\section{R. A. Beaumont}

University of Washington

Seattle 5 , Washington

\author{
A. L. Whiteman
}

University of Southern California

Los Angeles 7, California

E. G. Straus

University of California

Los Angeles 24, California

\section{ASSOCIATE EDITORS}
E. F. BECKENBACH
A. HORN
L. NACHBIN
G. SZEKERES
C. E. BURGESS
V. GANAPATHY IYER
I. NIVEN
F. WOLF
M. HALL
R. D. JAMES
T. G. OSTROM
E. HEWITT
M. S. KNEBELMAN
M. M. SCHIFFER
K. YOSIDA

\section{SUPPORTING INSTITUTIONS}

\author{
UNIVERSITY OF BRITISH COLUMBIA \\ CALIFORNIA INSTITUTE OF TECHNOLOGY \\ UNIVERSITY OF CALIFORNIA \\ MONTANA STATE UNIVERSITY \\ UNIVERSITY OF NEVADA \\ OREGON STATE COLLEGE \\ UNIVERSITY OF OREGON \\ UNIVERSITY OF SOUTHERN CALIFORNIA
}

\author{
STANFORD UNIVERSITY \\ UNIVERSITY OF UTAH \\ WASHINGTON STATE COLLEGE \\ UNIVERSITY OF WASHINGTON \\ * * * * \\ AMERICAN MATHEMATICAL SOCIETY \\ CALIFORNIA RESEARCH CORPORATION \\ HUGHES AIRCRAFT COMPANY \\ THE RAMO-WOOLDRIDGE CORPORATION
}

Mathematical papers intended for publication in the Pacific Journal of Mathematics should be typewritten (double spaced), and the author should keep a complete copy. Manuscripts may be sent to any of the editors. All other communications to the editors should be addressed to the managing editor, E. G. Straus at the University of California, Los Angeles 24, California.

50 reprints per author of each article are furnished free of charge; additional copies may be obtained at cost in multiples of 50 .

The Pacific Journal of Mathematics is published quarterly, in March, June, September, and December. The price per volume (4 numbers) is $\$ 12.00$; single issues, $\$ 3.50$. Back numbers are available. Special price to individual faculty members of supporting institutions and to individual members of the American Mathematical Society: $\$ 4.00$ per volume; single issues, $\$ 1.25$.

Subscriptions, orders for back numbers, and changes of address should be sent to Pacific Journal of Mathematics, 2120 Oxford Street, Berkeley 4, California.

Printed at Kokusai Bunken Insatsusha (International Academic Printing Co., I.td.), No. 10, 1-chome, Fujimi-cho, Chiyoda-ku, Tokyo, Japan.

PUBLISHED BY PACIFIC JOURNAL OF MATHEMATICS, A NON-PROFIT CORPORATION

The Supporting Institutions listed above contribute to the cost of publication of this Journal, but they are not owners or publishers and have no responsibility for its content or policies. 


\section{Pacific Journal of Mathematics}

\section{Vol. 8, No. 2 \\ April, 1958}

John Herbert Barrett, Second order complex differential equations with a real independent variable ............................ 187

Avner Friedman, Remarks on the maximum principle for parabolic equations and its applications ......................... 201

Richard Robinson Goldberg, An inversion of the Stieltjes transform ....... 213

Olavi Hellman, On the periodicity of the solution of a certain nonlinear integral equation .................................. 219

Gilbert Helmberg, A theorem on equidistribution on compact groups...... 227

Lloyd Kenneth Jackson, Subfunctions and the Dirichlet problem ......... 243

Naoki Kimura, The structure of idempotent semigroups. I ............ 257

Stephen Kulik, A method of approximating the complex roots of equations........................................ 277

Ancel Clyde Mewborn, A note on a paper of L. Guttman.............. 283

Zeev Nehari, On the principal frequency of a membrane ............ 285

G. Pólya and I. J. Schoenberg, Remarks on de la Vallée Poussin means and convex conformal maps of the circle ...................... 295

B. M. Stewart, Asymmetry of a plane convex set with respect to its centroid .......................................... 335

Hans F. Weinberger, Lower bounds for higher eigenvalues by finite difference methods

Edwin Weiss and Neal Zierler, Locally compact division rings ......... 369

Bertram Yood, Homomorphisms on normed algebras ................. 373 